2. Бочарова О.В. Особенности состояния здоровья детей в зависимости от физического развития на педиатрическом участке // Вестник современных ис-следований. - 2018. - № 4.2 (19). - С. 37 - 39.

3. Арустамян М.А. Мониторинг физического развития детей до года г. Еревана // Евразийский союз ученых. - 2019. - № 12-2 (69).- С. 44-48.

4. Гаджикеримов Г.Э., Аль - Зрер К.М. Основные тенденции заболеваемо-сти детей от рождения до 14 лет в Российской Федерации // Российский педиат-рический журнал. - 2020, т: 23. - № 6. - С. 396.

5. Давыдова А.В., Логачев М.Ф. Актуальные проблемы развития повы-шенной массы тела и ожирения у детей и подростков // Детская больница. - 2014. - № 1.- С. 31 - 36.

6. Матосян К.А., Оранская А.Н., Пустовалов Д.А., Черепкова Е.В., Скот-никова Ю.В., Бурдюкова Е.В., Анищенко А.П., Гуревич К.Г., Ханферьян Р.А. Особенности качественного состава жировой ткани в организме в пубертатном и постпубертатном возрасте с учетом возраста, пола, уровня физической активно-сти и характера питания // Вопросы питания. - 2015. - № 5.- С. 88 - 94.

7. Романцова Т.И. Молекулярные механизмы регуляции массы тела как мишени патогенетической терапии ожирения // Терапия. - 2015. - № 4 (4). - С. 71-78.

8. Ненашева А.В., Аминов А.С. Физическое развитие и физическая подго-товленность детей 6-14 лет из социально неблагополучных семей, эффектив-ность системы реабилитации // Теория и практика физической культуры. - 2015. - № 4. - С. 59-61.

9. Шевцов А.В. Современные образовательные возможности для развития физической реабилитации в направлении «адаптивная физическая культура» // Адаптивная физическая культура. - 2020. - т. 82. - № 2. - С. 6 - 9.

10. Пичугина Е.В. Развитие направления физической реабилитации лиц молодого и старшего возраста средствами адаптивной физической культуры в физкультурно - оздоровительном учреждении // MODERN SCIENCE. - 2019. - № 6-1. - С. 49-56.

11. Маскова Г.С. Прогноз эффективности реабилитационного лечения де-тей с ожирением в поликлинике // Практическая медицина. - 2020. - Т.18. - № 6. - С. 170 - 175.

12. Черных С.П., Руднев С.Г., Николаев Д.В., Старунова О.А. Физическое развитие и состав тела российских детей по данным биоимпедансного обследо-вания в центрах здоровья // Вопросы питания. - 2014. - т. 83. - № S3. - С. 46.

13. Paul Simmet, K George Mm Alberti, Francine Kaufman, Naoko Tajima, Martin Silink, Silva Arslanian, Gary Wong, Peter Bennett, Jonathan Shaw, Sonya Caprio. The metabolic syndrome in children and adolescents - an IDF consensus re-port // Pediatr Diabetes. - 2007. - № 8.- P. 299 - 306.

14. Кузнецова Н.С., Бондарь Г.Н., Крукович Е.В. Способ диагностики степеней риска развития метаболических нарушений у детей и подростков на этапах их онтогенеза: рац. предложение; Тихоок. гос. мед. ун-т. - Владивосток, 2013. - 11 с. (заявл. 5.11.2013; выд. удостоверение № 2817 2.12.2013).

15. Кузнецова Н.С., Бондарь Г.Н., Крукович Е.В., Хмельницкая Е.А. Спо-соб дифференцированной физической нагрузки в зависимости от величины ин-декса массы тела (ИМТ) у детей и подростков. рац. предложение; Тихоок. гос. мед. ун-т. - Владивосток, 2013. - 14 с. (заявл. 25.12.2013; выд. удостоверение № 2821 10.01.2014).

16. Кузнецова Н.С., Крукович Е.В., Бондарь Г.Н. Способ оценки результа-тов исследования структурно-телесных компонентов организма и липидного спектра у детей и подростков: рац. предложение; Тихоок. гос. мед. ун-т. - Вла-дивосток, 2013. - 12 с. (Заявл. 14.08.2013; выд. удостоверение № 28162.12 .2013$)$.

\title{
Кязимова В.А., Гахраманова С.М., Бахшалиев А.Б. Показатели липидного профиля крови у больных с артериальной гипертензией в зависимости от уровня витамина D
}

Азербайджанский Медицинский Университет Министерства Здравоохранения Азербайджанской Республики (Азербайджан, Баку)

doi 10.18411/gq-15-10-2021-02

Как известно, эссенциальная артериальная гипертензия (АГ) является полиморбидным заболеванием, к факторам риска развития которой относятся как наследственная предрасположенность, так и нарушения липидного, минерального обмена, гормонального статуса [1-3]. Исследования последних лет подчеркивают важность увеличения плазменного уровня витамина D для уменьшения риска различных дислипидемий, ассоциированных с такими кардиоваскулярными 
заболеваниями, как АГ, инсульт, инфаркт миокарда [4-8]. Регулярное поддержание нормального уровня витамина $\mathrm{D}$ способствует двукратному уменьшению риска развития атеросклероза, что имеет важное значение в профилактике СС3.

Цель исследования - изучение особенностей изменения параметров липидного спектра крови у больных с артериальной гипертензией в зависимости от концентрации витамина D.

\section{Материал и методы}

Одномоментное клиническое исследование проводилось сотрудниками кафедры Клинической фармакологии на базе Кардиологического Отделения Терапевтической Клиники Азербайджанского Медицинского Университета в период с сентября 2018 по январь 2020 года.

В исследование вошли 34 больных с установленным ранее диагнозом: артериальная гипертония (АГ) 1-2 степени по классификации Европейского Общества Кардиологов и Европейского Общества по Гипертонии 2018 года (2018 ESC/ESH

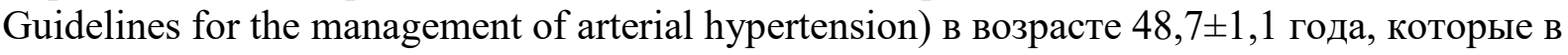
зависимости от уровня витамина D были разделены на 2 группы. В первую группу (группа I) вошли 19 больных (8 мужчин и 11 женщин) с низкими значениями уровня витамина D (0-30 нг/мл), а во вторую (группа II) - 15 пациентов (6 мужчин и 9 женщин) с оптимальными значениями уровня витамина D (30-60 нг/мл) согласно клиническим рекомендациям Российской ассоциации эндокринологов по диагностике, лечению и профилактике дефицита витамина D у взрослых 2016 года. Пациенты не принимали холестерин снижающих препаратов и постоянную гипотензивную терапию. Контрольную группу сравнения составили 17 практически здоровых добровольцев (7 мужчин и 10 женщин) без артериальной гипертензии с оптимальными значениями уровня витамина D (30-60 нг/мл) в среднем возрасте $43,4 \pm 0,9$ года.

Содержание витамина D в организме больных с АГ и здоровых добровольцев определялось путем определения гидроксивитамина D $(25(\mathrm{OH}) \mathrm{D})$ в плазме крови иммуноферментным методом. Показатели липидного спектра крови изучали на основании анализа содержания общего холестерина (ОХC), липопротеидов низкой и очень низкой плотности (ЛПНП, ЛПОНП), липопротеидов высокой плотности (ЛПВП), триглицеридов (ТГ) иммуноферментным методом.

В исследование не включались пациенты с АГ 3-степени, симптоматическими АГ, гипертоническими кризами, ишемической болезнью сердца (ИБС) III-IV ФК, хронической сердечной недостаточностью (XCH) III-IV ФК, сахарным диабетом (СД) 1 и 2 типа, хронической почечной недостаточностью 3-5 стадии, тяжелой печеночной недостаточностью, заболеваниями щитовидной железы, надпочечников, онкологическими заболеваниями.

При статистической обработке результатов исследования использовался пакет прикладных программ Statistica 10,0 фирмы StatSoft.Inc (США). Данные представлялись в виде числа наблюдений (п), среднего значения признака (M), стандартного отклонения (SD). В виду асимметричности распределения проверка нулевой гипотезы проводилась с использованием непараметрического критерия U (Вилкоксона-Манна-Уитни). В качестве порогового уровня статистической значимости принималось значение $\mathrm{p}<0,05$.

\section{Результаты и обсуждение}

Большинство исследований последних лет доказывают благоприятное влияние оптимального уровня витамина D на поддержание нормального баланса липидного спектра крови [4;5;7]. Анализируя результаты 10 плацебо-контролируемых двойных слепых исследований с витамином D, Jorde R. с соавторами в 2011 году показали положительную связь сывороточного витамина D c антиатерогенными липопротедами высокой плотности и отрицательную с атерогенными липопротеидами низкой плотности [4]. Корейские ученые в 2019 году изучили взаимосвязь между уровнем 
витамина D и липидным профилем у 243 здоровых детей, не страдающих ожирением [5]. Исследованные были разделены на 2 группы: на группу с дефицитом витамина D $(<20$ нг/мл) и на группу с нормальным содержанием витамина D (>20 нг/мл). Группа с дефицитом данного витамина показала более высокий уровень триглицеридов $(90,27$ против 74,74 ммоль). Исследователи пришли к выводу, что уровень витамина D, по видимому, влияет на липидный профиль даже не страдающих ожирением детей. B другое исследование вошли больные с ранней диабетической нефропатией и с дефицитом витамина $\mathrm{D}$, которые ежемесячно получали $50000 \mathrm{ME}$ витамина D внутримышечно в течение 6 месяцев. В результате терапии витамином D значительно снизились величины ДАД, общего холестерина, атерогенных липопротеидов низкой плотности [7].

У исследованных нами больных с АГ при низких значениях содержания витамина D в крови ( $<30$ нг/мл) наблюдаются более высокие концентрации атерогенных и низкие концентрации антиатерогенных липопротеидов, по сравнению с пациентами с оптимальным уровнем витамина D и здоровыми добровольцами. Так, уровень атерогенных ЛПНП и ЛПОНП у больных I группы, был, соответственно, на $20,9 \%, p<0,05$ и на 50,2\%, p<0,001выше, чем у пациентов II группы, и на 29,9\%, p<0,01 и на $57,6 \%, \mathrm{p}<0,001$ больше, чем в группе контроля. Кроме того, в 1-ой группе наблюдались более высокие концентрации ТГ - соответственно, на 32,4\% и на 34,1\%, $\mathrm{p}<0,01$, по сравнению с больными с оптимальным уровнем витамина $\mathrm{D}$ и здоровыми добровольцами. В величинах уровня антиатерогенных ЛПВП существенной достоверной разницы между больными 1-ой и 2-ой групп не было обнаружено. Лишь у больных с низким уровнем витамина D значения ЛПВП были 21,7\%, p $<0,05$ ниже, чем в контрольной группе. В результате вышеописанных изменений уровень ОХС у пациентов с низким уровнем витамина D оказался достоверно выше, чем в других сравниваемых группах $(\mathrm{P}<0,05)$. Аналогичные данные получены в исследованиях других авторов, среди которых особое внимание привлекает проведенное в 2019 году исследование по влиянию витамина D на показатели липидного спектра крови [6], в котором величины ЛПНП и ТГ при недостаточности данного витамина были выше на $61,4 \%$ и на 45,9\%, а уровень ЛПВП был ниже на 27,0\%, по сравнению с пациентами с нормальными значениями витамина D. Авторы приходят к выводу, что дислипидемия может быть результатом недостаточности или дефицита витамина D. Другие авторы отмечают, что дефицит витамина D является независимым предиктором повышения уровня триглицеридов [8]. Исходя из полученных данных можно предположить, что витамин D вносит свой вклад в поддержание антиатерогенного потенциала плазмы у больных с АГ за счет регулирования иммунной воспалительной реакции в интиме сосудов и ингибирования пролиферации гладкомышечных клеток сосудов.

Заключение. Таким образом, низкий уровень витамина D у больных с АГ ассоциируется с усилением процессов атерогенеза.

$$
\text { *** }
$$

1. Skaaby T, Thuesen BH, Linneberg A. Vitamin D, Cardiovascular Disease and Risk Factors. Adv Exp Med Biol. 2017; 996: 221-230. https://doi.org/ 10.1007/978-3-319-56017-5_18

2. Alkippi N, Marina T, Nikolaos M, Anargyros M, Anastassios P, and Michael K. Vitamin D in cardiovascular disease, In Vivo September-October 2018 vol. 32 no. 5 977-981. https://doi.org/ 10.21873/invivo. 11338

3. Antonio JL, Jamerson RC, Maria LGR, Diego BCB. Vitamin D Deficiency and Cardiovascular Diseases, Int. J. Cardiovasc. Sci. vol.31 no.4 Rio de Janeiro July/Aug. 2018 Epub May 21, 2018, http://dx.doi.org/10.5935/2359-4802.20180025

4. Jorde R, Grimnes G. Vitamin D and metabolic health with special reference to the effect of vitamin D on serum lipids. Prog Lipid Res. 2011; 50(4): 303-312. https://doi.org/ 10.1016/j.plipres.2011.05.001. [PubMed] [Cross Ref]

5. Mi Ra Kim and Su Jin Jeong *.Relationship between Vitamin D Level and Lipid Profile in Non-Obese Children. Metabolites 2019, 9, 125; https://doi.org/ 10.3390/metabo9070125 
6. Nabil Ahmad Bashir1, Adnan Ahmad Mohammad Bashir, Hani Adnan Bashir Effect of Vitamin D deficiency on Lipid Profile. American Journal of Laboratory Medicine 2019; 4(1): 11-18 https://doi.org/ 10.11648/j.ajlm.20190401.12

7. Liyanage GC1, Lekamwasam S2, Weerarathna TP2, Liyanage CE3 Effects of high-dose parenteral vitamin D therapy on lipid profile and blood pressure in patients with diabetic nephropathy: A randomized double-blind clinical trial. Diabetes Metab Syndr. 2017 Dec; 11 Suppl 2: S767-S770. https://doi.org/ 10.1016/j.dsx.2017.05.013. Epub 2017 Jun 3.

8. Rodriguez-Rodriguez E., Ortega R.M., Gonzalez-Rodriguez L.G., Lopez-Sobaler A.M. for UCM Research Group VALORNUT. Vitamin D deficiency is an independent predictor of elevated triglycerides in Spanish school children. Eur J Nutr 2011; 50(5):373-8. https://doi.org/ 10.1007/s00394-010-0145-4 